\title{
Fuzzified Data Based Neural Network Modeling for Health Assessment of Multistorey Shear Buildings
}

\author{
Deepti Moyi Sahoo and S. Chakraverty \\ Department of Mathematics, National Institute of Technology Rourkela, Rourkela, Odisha 769 008, India \\ Correspondence should be addressed to S. Chakraverty; sne_chak@yahoo.com
}

Received 21 November 2012; Revised 14 February 2013; Accepted 15 February 2013

Academic Editor: Matt Aitkenhead

Copyright (c) 2013 D. M. Sahoo and S. Chakraverty. This is an open access article distributed under the Creative Commons Attribution License, which permits unrestricted use, distribution, and reproduction in any medium, provided the original work is properly cited.

\begin{abstract}
The present study intends to propose identification methodologies for multistorey shear buildings using the powerful technique of Artificial Neural Network (ANN) models which can handle fuzzified data. Identification with crisp data is known, and also neural network method has already been used by various researchers for this case. Here, the input and output data may be in fuzzified form. This is because in general we may not get the corresponding input and output values exactly (in crisp form), but we have only the uncertain information of the data. This uncertain data is assumed in terms of fuzzy number, and the corresponding problem of system identification is investigated.
\end{abstract}

\section{Introduction}

System identification methods in structural dynamics, in general, solve inverse vibration problems to identify properties of a structure from measured data. The rapid progress in the field of computer science and computational mathematics during recent decades has led to an increasing use of process computers and models to analyze, supervise, and control technical processes. The use of computers and efficient mathematical tools allows identification of the process dynamics by evaluating the input and output signals of the system. The result of such a process identification is usually a mathematical model by which the dynamic behaviour can be estimated or predicted. The system identification problem has been nicely explained in a recent paper [1]. The same statements from [1] are reproduced below for the benefit of the readers.

The study of structures dynamic behaviour may be categorized into two distinct activities: analytical and/or numerical modelling (e.g., finite element models) and vibration tests (e.g., experimental modal models). Due to different limitations and assumptions, each approach has its advantages and shortcomings. Therefore, in order to determine the dynamic properties of the structure, reconciliation processes including model correlation and/or model updating should be performed. Model updating can be defined as the adjustment of an existing analytical/numerical model in the light of measured vibration test. After adjustment, the updated model is expected to represent the dynamic behaviour of the structure more accurately as proposed by Friswell et al. [2]. With the recent advances in computing technology for data acquisition, signal processing, and analysis, the parameters of structural models may be updated from the measured responses under excitation of the structure. This procedure is achieved using system identification techniques as an inverse problem. The inverse problem may be defined as determination of the internal structure of a physical system from the system's measured behaviour, or estimation of an unknown input that gives rise to a measured output signal according to Tanaka and Bui [3].

Comprehensive literature surveys have been provided on the subject of model updating of the structural systems by Alvin et al. [4], and Time series methods for fault detection and identification in vibrating structures were presented by Fassois and Sakellariou [5]. Shear buildings are among the most widely studied structural systems. Previous works on model updating of shear buildings rely mostly on using modal parameter identification and physical or structural parameter 


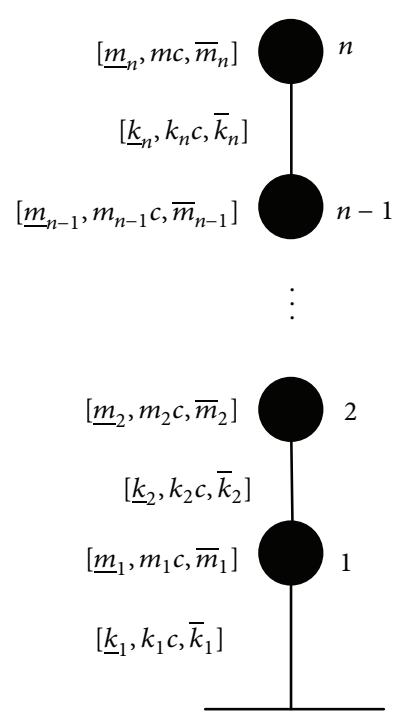

FIGURE 1: Multistorey shear structure with $n$-levels having fuzzy structural parameters.

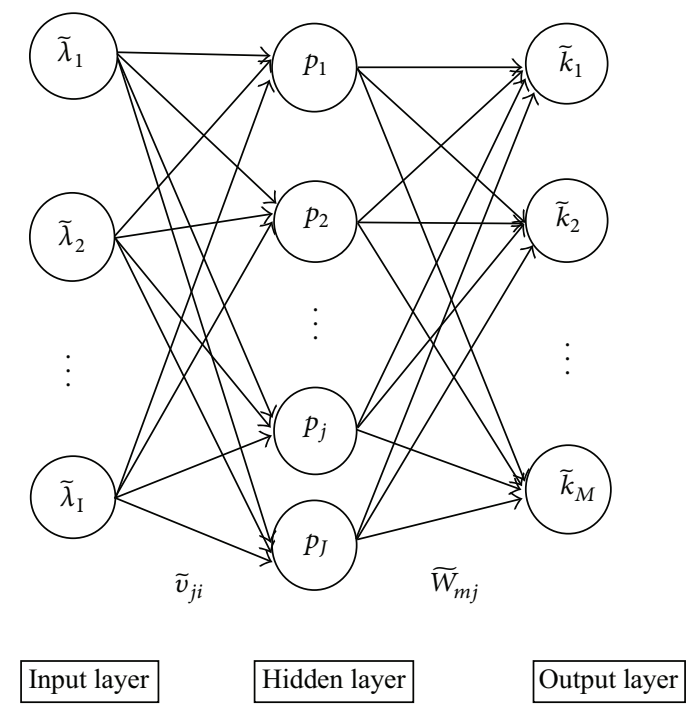

FiguRE 2: Layered feed-forward fuzzy neural network.

identification to drive the corresponding update procedures. As regards the publications, Marsi et al. [6] gave various methodologies for different types of problems in system identification. Various techniques for improving structural dynamic models were reviewed in a review paper by Ibanez [7], and studies made by Datta et al. [8] related to system identification of buildings done until that date were also surveyed. Some of the related publications may be mentioned as those of Loh and Tou [9] and Yuan et al. [10].

It is known that, the systems which may be modeled as linear, the identification problem often turns in to a non-linear optimization problem. This requires an intelligent iterative scheme to have the required solution. There exists various online and offline methods, namely, the GaussNewton, Kalman filtering and probabilistic methods such

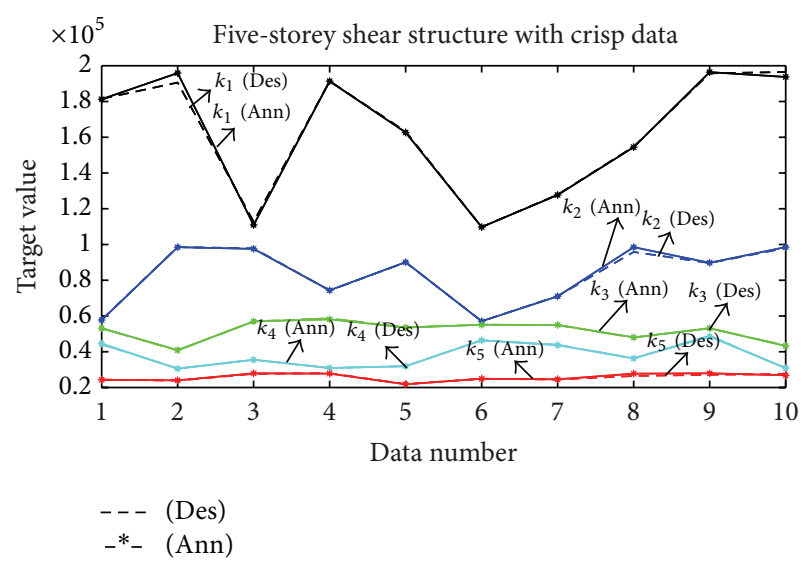

FIgUre 3: Comparison between the desired and the ANN values of $\widetilde{K}$ for a single-storey shear structure.

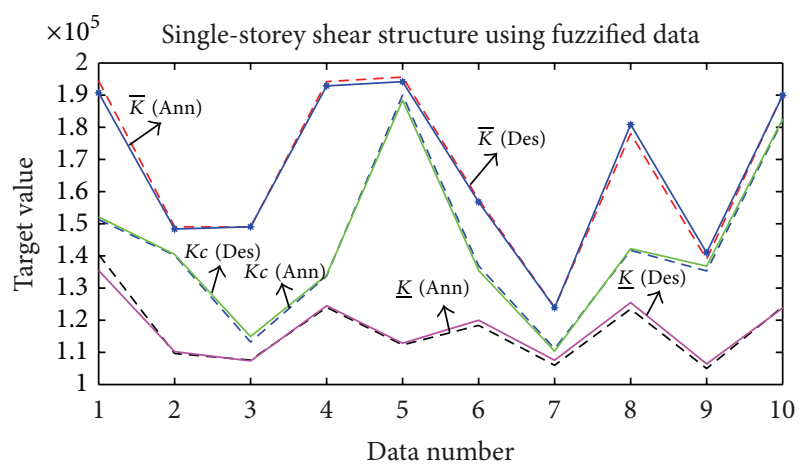

FIGURE 4: Comparison between the desired and the ANN values of $\widetilde{K}$ for a single-storey shear structure.

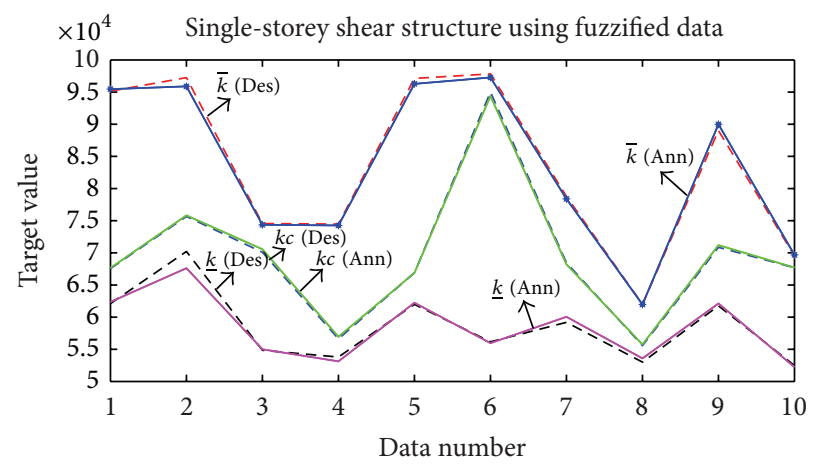

FIgURE 5: Comparison between the desired and the ANN values of $\widetilde{K}$ for a single-storey shear.

as maximum likelihood estimation, and so forth. However, the identification problem for a large number of parameters, following two basic difficulties are faced often:

(i) objective function surface may have multiple maxima and minima, and the convergence to the correct parameters is possible only if the initial guess is considered as close to the parameters to be identified; 


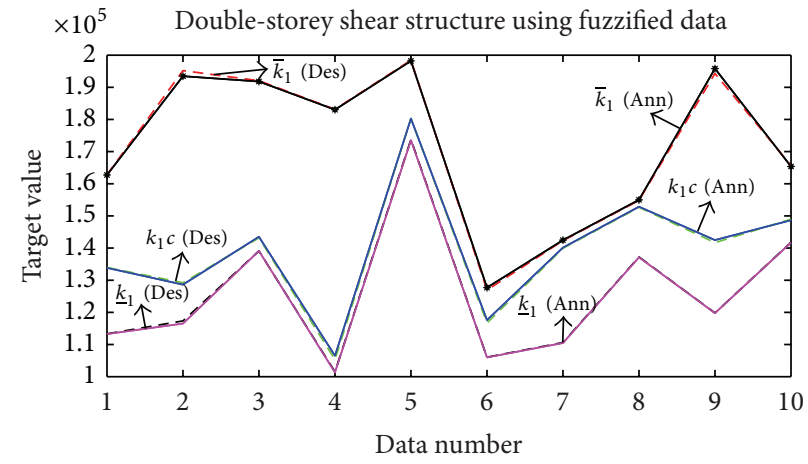

(a)

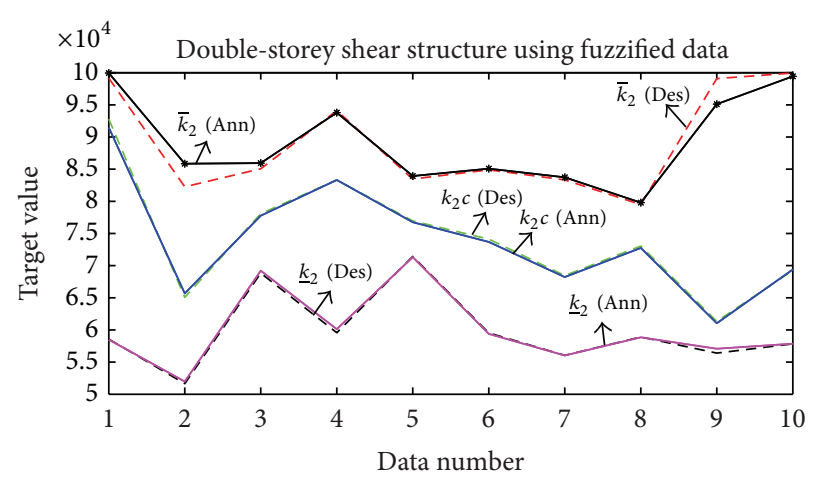

(b)

FIgurE 6: (a) Comparison between the desired and the ANN values of $\widetilde{k}_{1}$ for a double-storey shear structure. (b) Comparison between the desired and the ANN values of $\widetilde{k}_{2}$ for a double-storey shear structure.

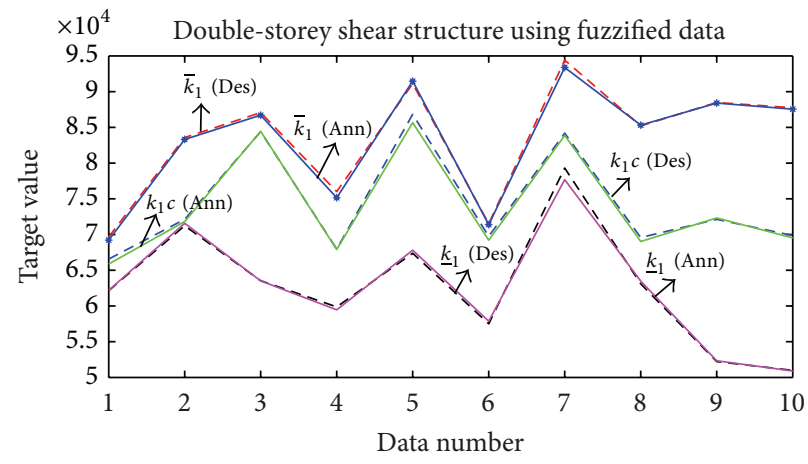

(a)

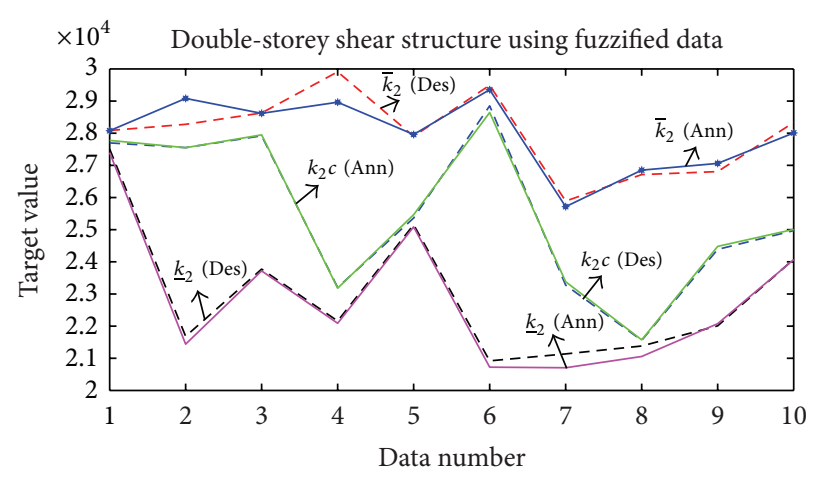

(b)

Figure 7: (a) Comparison between the desired and the ANN values of $\widetilde{k}_{1}$ for a double-storey shear structure. (b) Comparison between the desired and the ANN values of $\widetilde{k}_{2}$ for a double-storey shear structure.

(ii) inverse problem in general gives nonunique parameter estimates.

To overcome these difficulties, researchers have developed various identification methodologies for the said problem by using powerful technique of Artificial Neural Network (ANN). Chen [11] presented a neural network based method for determining the modal parameters of structures from field measurement. Using the observed dynamic responses, he trained the neural network based on back-propagation technique. He then directly identified the modal parameters of the structure using the weight matrices of the neural network. In particular, Huang et al. [12] presented a novel procedure for identifying the dynamic characteristics of a building using a back-propagation neural network technique. Another novel neural network based approach has been presented by Kao and Hung [13] for detecting structural damage. A decentralized stiffness identification method with neural networks for a multidegree of freedom structure has been developed by $\mathrm{Wu}$ et al. [14]. Localized damage detection and parametric identification method with direct use of earthquake responses for large-scale infrastructures has also been proposed by $\mathrm{Xu}$ et al. [15]. A neural network based strategy by $\mathrm{Xu}$ et al. [16] was developed for direct identification of structural parameters from the time domain dynamic responses of an object structure without anyeigen value analysis.

System identification on the other hand tries to identify structural matrices of mass, damping and stiffness directly. Among various methodologies in this regard Chakraverty [17], Perry et al. [18], Wang [19], Yoshitomi and Takewaki [20], and $\mathrm{Lu}$ and $\mathrm{Tu}$ [21] developed different techniques to handle the system identification problems. Yuan et al. [10] developed a methodology that identifies the mass and stiffness matrices of a shear building from the first two orders of structural mode measurement. Koh et al. [22] proposed several Gabased substructural identification methods, which work by solving parts of the structure at a time to improve the convergence of mass and stiffness estimates particularly for large systems. Chakraverty [17] proposed procedures to refine the methods of Yuan et al. [10] to identify the structural mass and stiffness matrices of shear buildings from the modal test data. The refinement was obtained using Holzer criteria. Tang et al. [23] utilized a differential evolution (DE) strategy for parameter estimation of the structural systems with limited output data, noise polluted signals, and no prior 


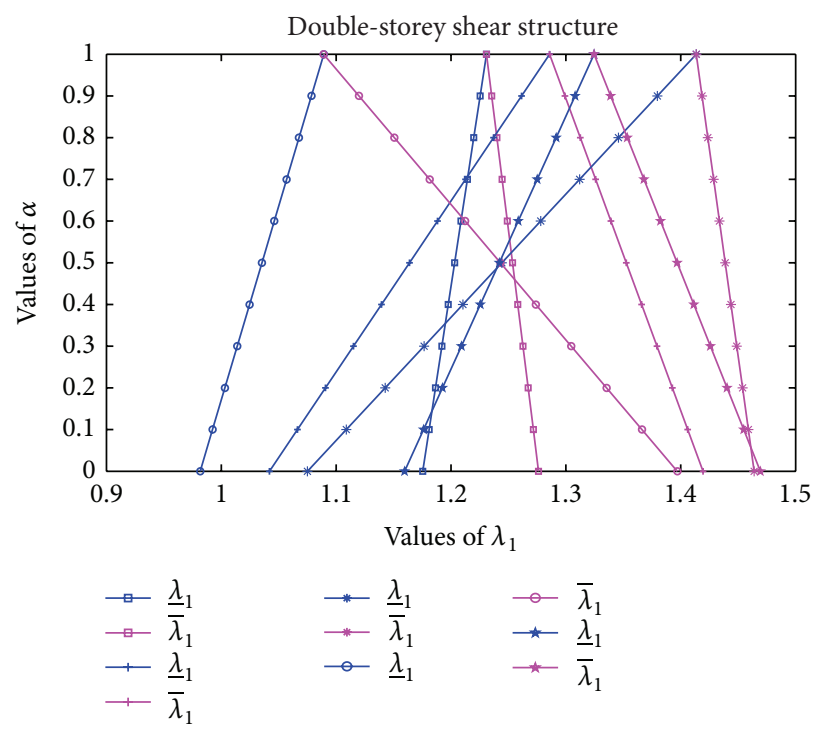

(a)

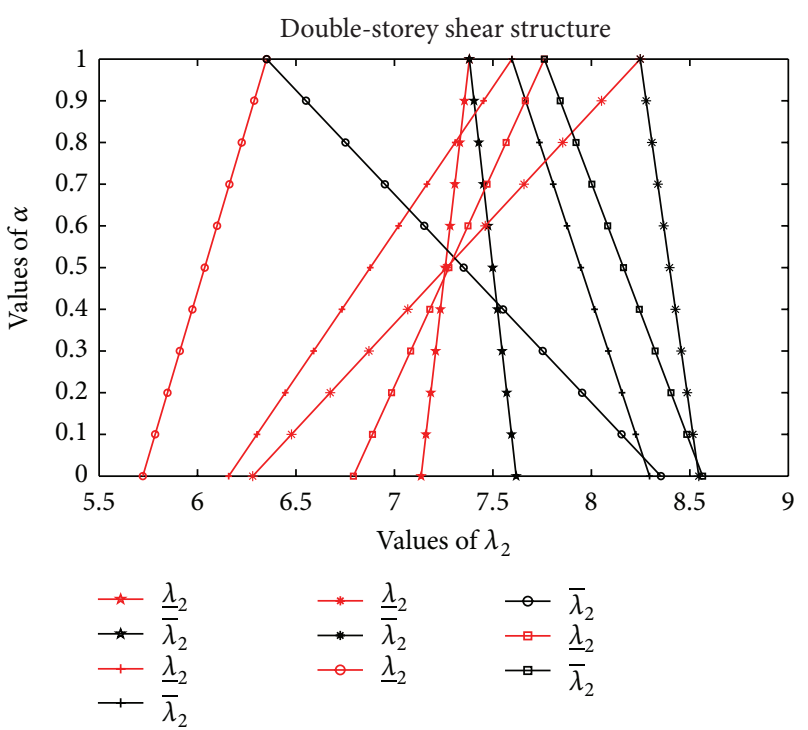

(b)

Figure 8: (a) Comparison of $\lambda_{1}$ and $\overline{\lambda_{1}}$ with respect to $\alpha$. (b) Comparison of $\lambda_{2}$ and $\overline{\lambda_{2}}$ with respect to $\alpha$.

knowledge of mass, damping, or stiffness matrices. Recent works on model updating of multistory shear buildings for simultaneous identification of mass, stiffness, and damping matrices using two different soft-computing methods have been developed by Khanmirza et al. [1]. It may be seen from above that Artificial Neural Networks (ANNs) provide a fundamentally different approach to system identification. They have been successfully applied for identification and control of dynamics systems in various fields of engineering because of excellent learning capacity and high tolerance to partially inaccurate data.

It is revealed from the above literature review that various authors developed different identification methodologies using ANN. They supposed that the data obtained are in exact or crisp form. But in actual practice the experimental data obtained from equipments are with errors that may be due to human or equipment error, thereby giving uncertain form of the data. Although one may also use probabilistic methods to handle such problems. Then, the probabilistic method requires huge quantity of data which may not be easy or feasible. Thus in this paper, a minimum number of data are taken in fuzzified form to have the essence of the uncertainty. Accordingly, in this paper, identification methodologies for multistorey shear buildings have been proposed using the powerful technique of Artificial Neural Network (ANN) models which can handle fuzzified data. It is already mentioned that identification with crisp data is known and also neural network method has already been used by various researchers for this case. Here, the input and output data may be in fuzzified form. This is because in general we may not get the corresponding input and output values exactly (in crisp form), but we have only the uncertain information of the data. This uncertain data has been assumed to be in terms of fuzzy numbers.
In this paper, the initial design parameters, namely, stiffness and mass and so the frequency of the said problem is known. But after a large span of time, the structure may be subjected to various manmade and natural calamities. Then, the engineers want to know the present health of the structure by system identification methods. It is assumed that only the stiffness is changed and the mass remains the same. As such equipments are available to get the present values of the frequencies and using these one may get the present parameter values by ANN. But while doing the experiment, one may not get the exact values of the parameters. But we may get those values as uncertain, namely, in fuzzy form. So if sensors are placed to capture the frequency of the floors in fuzzy (uncertain) form, then those may be fed into the proposed new ANN model to get the present stiffness parameters in fuzzified form. In order to train the new ANN model, set of data are generated numerically beforehand. As such, converged ANN model gives the present stiffness parameter values in interval form for each floor. Thus, one may predict the health of the uncertain structure. Corresponding example problems have been solved, and related results are reported to show the reliability and powerfulness of the model.

\section{Analysis and Modelling}

System identification refers to the branch of numerical analysis which uses the experimental input and output data to develop mathematical models of systems which finally identify the parameters. The floor masses for this methodology are assumed to be $\left[m_{1}, m_{1} c, \overline{m_{1}}\right]$, $\left[\underline{m_{2}}, m_{2} c, \overline{m_{2}}\right], \ldots,\left[\underline{m_{n}}, m_{n} c, \overline{m_{n}}\right]$, and the stiffness $\left[\underline{k_{1}}, k_{1} c\right.$, $\left.\left.\overline{k_{1}}\right],\left[k_{2}, k_{2} c, \overline{k_{2}}\right], \ldots, \overline{\left[k_{n}\right.}, k_{n} c, \overline{k_{n}}\right]$ are the structural parameters which are to be identified. It may be seen that all the mass 
and stiffness parameters are taken in fuzzy form. As such here for each mass $m_{i}$, we have $m_{i}$ as the left value, $m_{i} c$ as the centre value, and $\overline{m_{i}}$ as the right value. Similarly for the stiffness parameter for each mass $k_{i}$, we have $\underline{k_{i}}$ as the left value, $k_{i} c$ as the centre value, and $\overline{k_{i}}$ as the right value. The $\mathrm{n}$-storey shear structure is shown in Figure 1. Corresponding dynamic equation of motion for $\mathrm{n}$-storey (supposed as $\mathrm{n}$ degrees of freedom) shear structure without damping may be written as

$$
\{\widetilde{M}\}\{\ddot{\widetilde{X}}\}+\{\widetilde{K}\}\{\widetilde{X}\}=\{\widetilde{0}\},
$$

where $\{\ddot{\ddot{x}}\}=\{\underline{\ddot{x}}, \ddot{x} c, \overline{\ddot{x}}\}, \quad\{\tilde{x}\}=[\underline{x}, x c, \bar{x}]$.

$\{\widetilde{M}\}=[\underline{M}, M c, \bar{M}]$ is $n \times n$ mass matrix of the structure and is given by

$$
\{\widetilde{M}\}=\left[\begin{array}{ccccc}
{\left[\underline{m_{1}}, m_{1} c, \overline{m_{1}}\right]} & 0 & \ldots & \ldots & 0 \\
0 & {\left[\underline{m_{2}}, m_{2} c, \overline{m_{2}}\right]} & 0 & \ldots & 0 \\
\ldots & \ldots & \ldots & \ldots & \ldots \\
\ldots & \ldots & 0 & {\left[\underline{m_{n-1},}, \overline{\left.m_{n-1} c, \overline{m_{n-1}}\right]}\right]} & {\left[\underline{m_{n}, m_{n} c, \overline{m_{n}}}\right]} \\
0 & \ldots & \ldots & 0
\end{array}\right]
$$

$\{\widetilde{K}\}=[\underline{K}, K c, \bar{K}]$ is $n \times n$ stiffness matrix of the structure and may be written as

$$
\{\widetilde{K}\}=\left[\begin{array}{ccccc}
\widetilde{k}_{1}+\widetilde{k}_{2} & \widetilde{k}_{2} & 0 & \cdots & 0 \\
-\widetilde{k}_{2} & \widetilde{k}_{2}+\widetilde{k}_{3} & -\widetilde{k}_{3} & \cdots & 0 \\
\cdots & \cdots & & & \cdots \\
0 & \cdots & -\widetilde{k}_{n-1} & \widetilde{k}_{n-1}+\widetilde{k}_{n} & \widetilde{k}_{n} \\
0 & & \cdots & -\widetilde{k}_{n} & \widetilde{k}_{n}
\end{array}\right]
$$

and $\{\widetilde{X}\}=\left\{\widetilde{x}_{1}, \widetilde{x}_{2}, \ldots, \widetilde{x}_{n}\right\}^{T}$ are the vectors of displacement.

We will first solve the above free vibration equation for vibration characteristics, namely, for frequency and mode shapes of the said structural system in order to get the stiffness parameters in fuzzified form. Accordingly putting $\{\widetilde{X}\}=$ $\{\widetilde{\phi}\} e^{i(\widetilde{\omega}) t}$ in free vibration equation (1), we get

$$
\left(\{\widetilde{K}\}-\{\widetilde{M}\}[\widetilde{\omega}]^{2}\right)\{\widetilde{\phi}\}=\{\widetilde{0}\},
$$

where $\{\widetilde{\omega}\}^{2}=[\underline{\omega}, \omega c, \bar{\omega}]^{2}=[\underline{\lambda}, \lambda c, \bar{\lambda}]$ are eigenvalues or the natural frequency and $\{\widetilde{\phi}\}$ are mode shapes of the structure, respectively.

\section{Basic Concept of Fuzzy Set Theory}

Definition 1. Let $X$ be a universal set. Then, the fuzzy subset $A$ of $X$ is defined by its membership function

$$
\mu_{A}: X \longrightarrow[0,1],
$$

which assigns a real number $\mu_{A}(x)$ in the interval $[0,1]$, to each element $x \in X$, where the value of $\mu_{A}(x)$ at $x$ shows the grade of membership of $x$ in $A$.

Definition 2. Given a fuzzy set $A$ in $X$ and any real number $\alpha \in[0,1]$, then, the $\alpha$-cut or $\alpha$-level or cut worthy set of $A$, denoted by $A_{\alpha}$, is the crisp set

$$
A_{\alpha}=\left\{x \in X \mid \mu_{A}(x) \geq \alpha\right\} .
$$

The strong $\alpha$-cut, denoted by $A_{\alpha+}$, is the crisp set

$$
A_{\alpha+}=\left\{x \in X \mid \mu_{A}(x) \geq \alpha\right\} .
$$

Definition 3. A fuzzy number is a convex normalized fuzzy set of the real line $R$ whose membership function is piecewise continuous.

Definition 4. A triangular fuzzy number $A$ can be defined as a triplet $\left[a_{1}, a_{2}, a_{3}\right]$. Its membership function is defined as

$$
\mu_{A}(x)= \begin{cases}0, & x<a_{1} \\ \frac{x-a_{1}}{a_{2}-a_{1}}, & a_{1} \leq x \leq a_{2} \\ \frac{a_{3}-x}{a_{3}-a_{2}}, & a_{2} \leq x \leq a_{3} \\ 0, & x>a_{3} .\end{cases}
$$

Above TFN may be transformed to an interval form $A_{\alpha}$ by $\alpha$-cut as

$$
A_{\alpha}=\left[a_{1}^{(\alpha)}, a_{3}^{(\alpha)}\right]=\left[\left(a_{2}-a_{1}\right) \alpha+a_{1},-\left(a_{3}-a_{2}\right) \alpha+a_{3}\right] .
$$

\section{Operation of Fuzzy Number}

In this section, we consider arithmetic operation on fuzzy numbers and the result is expressed in membership function:

$$
\forall x, y, z \in R \text {. }
$$

(1) Addition: $A(+) B$

$$
\mu_{A(+) B}(z)=\bigvee_{z=x+y}\left(\mu_{A}(x) \wedge \mu_{B}(y)\right) .
$$

(2) Subtraction: $A(-) B$

$$
\mu_{A(-) B}(z)=\bigvee_{z=x-y}\left(\mu_{A}(x) \wedge \mu_{B}(y)\right) .
$$

(3) Multiplication: $A(\cdot) B$

$$
\mu_{A(\cdot) B}(z)=\bigvee_{z=x \cdot y}\left(\mu_{A}(x) \wedge \mu_{B}(y)\right) .
$$


TABLE 1: Comparison between the desired and the ANN values of $k_{1}, k_{2}, k_{3}, k_{4}$, and $k_{5}$ for a five-storey shear structure.

\begin{tabular}{lcccccccccc}
\hline $\begin{array}{l}\text { Data } \\
\text { number }\end{array}$ & $k_{1}(\mathrm{Ann})$ & $k_{1}(\mathrm{Des})$ & $k_{2}(\mathrm{Ann})$ & $k_{2}$ (Des) & $k_{3}$ (Ann) & $k_{3}(\mathrm{Des})$ & $k_{4}(\mathrm{Ann})$ & $k_{4}(\mathrm{Des})$ & $k_{5}(\mathrm{Ann})$ & $k_{5}(\mathrm{Des})$ \\
\hline 1 & 181277.7318 & 181472.3686 & 57722.68 & 57880.6541 & 53111.561 & 53114.814 & 44531.8138 & 44120.9218 & 24304.5301 & 24387.4436 \\
2 & 195883.7223 & 190579.1937 & 98497.3362 & 98529.6391 & 40890.7789 & 40714.2336 & 30510.5884 & 30636.6569 & 24013.4116 & 23815.5846 \\
3 & 110889.324 & 112698.6816 & 97540.2878 & 97858.3474 & 56939.1333 & 56982.5861 & 35467.0709 & 35538.4597 & 27905.0723 & 27655.1679 \\
4 & 191334.6369 & 191337.5856 & 74367.0906 & 74268.7824 & 58151.3678 & 58679.865 & 30921.7444 & 30923.4278 & 27758.983 & 27951.999 \\
5 & 162671.148 & 163235.9246 & 90080.9291 & 90014.0234 & 53507.0758 & 53574.7031 & 31851.263 & 31942.6356 & 21775.0509 & 21868.726 \\
6 & 109757.8778 & 109754.0405 & 57034.3391 & 57094.3169 & 55073.904 & 55154.8026 & 46360.9403 & 46469.1566 & 24899.5619 & 24897.644 \\
7 & 127671.411 & 127849.8219 & 71003.1282 & 71088.0641 & 54999.758 & 54862.6494 & 43688.9611 & 43896.5725 & 24554.2598 & 24455.862 \\
8 & 154429.3614 & 154688.1519 & 98500.0073 & 95786.7763 & 48031.3148 & 47844.5404 & 36250.0047 & 36341.9896 & 27719.1389 & 26463.1301 \\
9 & 196399.16 & 195750.6835 & 89751.9025 & 89610.3665 & 53100.0372 & 53109.5578 & 48498.0106 & 49004.441 & 27950.5364 & 27093.6483 \\
10 & 193722.4668 & 196488.8535 & 98520.881 & 97974.6213 & 43228.929 & 43423.7338 & 30822.0268 & 30688.9216 & 26813.9637 & 27546.8668 \\
\hline
\end{tabular}

(4) Division: $A(/) B$

$$
\mu_{A(/) B}(z)=\bigvee_{z=x / y}\left(\mu_{A}(x) \wedge \mu_{B}(y)\right) .
$$

(5) Minimum: $A(\wedge) B$

$$
\mu_{A(\wedge) B}(z)=\bigvee_{z=x \wedge y}\left(\mu_{A}(x) \wedge \mu_{B}(y)\right) .
$$

(6) Maximum: $A(\vee) B$

$$
\mu_{A(\vee) B}(z)=\bigvee_{z=x \vee y}\left(\mu_{A}(x) \wedge \mu_{B}(y)\right) .
$$

\section{Artificial Neural Network (ANN) and Error-Back Propagation Training Algorithm (EBPTA) for Fuzzified Data}

Traditional ANN and EBPTA are well known, but here for the sake of completeness, those are developed for fuzzy case. In $\mathrm{ANN}$, the first layer is considered to be input layer and the last layer is the output layer. Between the input and output layers, there may be more than one hidden layer. Each layer will contain number of neurons or nodes (processing elements) depending upon the problem. These processing elements operate in parallel and are arranged in patterns similar to the patterns found in biological neural nets. The processing elements are connected to each other by adjustable weights. The input/output behavior of the network changes if the weights are changed. So, the weights of the net may be chosen in such a way so as to achieve a desired output. To satisfy this goal, systematic ways of adjusting the weights have to be developed to handle the fuzzified data which are known as training or learning algorithm. Neural network basically depends upon the type of processing elements or nodes, the network topology, and the learning algorithm. Here, error back-propagation training algorithm and feedforward recall have been used but to handle the uncertain system. The typical network is given in Figure 2.
In this Figure, $Z_{i}, P_{j}$, and $O_{m}$ are input, hidden, and output layers, respectively. The weights between input and hidden layers are denoted by $v_{j i}$, and the weights between hidden and output layers are denoted by $W_{k j}$. Here, $\widetilde{Z}_{i}=$ $\left[\begin{array}{lll}\lambda_{i} & \lambda_{i} c & \overline{\lambda_{i}}\end{array}\right]$ and $\widetilde{O}_{k}=\left[\begin{array}{llll}k_{m} & k_{m} c & \overline{k_{m}}\end{array}\right]$.

Given $R$ training pairs $\left\{\widetilde{Z}_{1}, \widetilde{d}_{1} ; \widetilde{Z}_{2}, \widetilde{d}_{2} ; \ldots, \widetilde{Z}_{R}, \widetilde{d}_{R}\right\}$ where $\widetilde{Z}_{i}(I \times 1)$ are input and $\tilde{d}_{i}(M \times 1)$ are desired values for the given inputs, the error value is computed as

$$
\widetilde{E}=\frac{1}{2}\left(\widetilde{d}_{m}-\widetilde{O}_{m}\right)^{2}, \quad m=1,2, \ldots M,
$$

for the present neural network as shown in Figure 2. The error signal terms of the output $\left(\widetilde{\delta}_{\mathrm{Om}}\right)$ and hidden layers $\left(\widetilde{\delta}_{p j}\right)$ are written, respectively, as

$$
\begin{gathered}
\widetilde{\delta}_{\mathrm{O} m}=0.5 *\left(\widetilde{d}_{m}-\widetilde{O}_{m}\right)\left(1-\widetilde{O}_{m}^{2}\right), \quad m=1,2, \ldots M, \\
\widetilde{\delta}_{P j}=0.5 *\left(1-\widetilde{P}_{j}^{2}\right) \sum_{m=1}^{M} \widetilde{\delta}_{\mathrm{O} m} \widetilde{W}_{P j}, \quad j=1,2, \ldots J .
\end{gathered}
$$

Consequently, output layer weights $\left(\widetilde{W}_{m j}\right)$ and hidden layer weights $\left(\widetilde{v}_{j i}\right)$ are adjusted as

$$
\begin{gathered}
\widetilde{W}_{m j}^{\text {(New) }}=\widetilde{W}_{m j}^{\text {(Old) }}+\eta \widetilde{\delta}_{O m} P_{j}, \quad m=1,2, \ldots M, j=1,2, \ldots J, \\
\widetilde{v}_{j i}^{\text {(New) }}=\widetilde{v}_{j i}^{\text {(Old) }}+\eta \widetilde{\delta}_{P j} Z_{i}, \quad j=1,2, \ldots J, i=1,2, \ldots I,
\end{gathered}
$$

where $\eta$ is the learning constant.

\section{Results and Discussion}

To investigate the present method here, examples of oneand two-storey shear structures are considered. So, for example, the floor masses for two-storey shear structure are $\left[\underline{m_{1}}, m_{1} c, \overline{m_{1}}\right],\left[\underline{m_{2}}, m_{2} c, \overline{m_{2}}\right]$ and the stiffnesses $\left[\underline{k_{1}}, k_{1} c, \overline{\left.k_{1}\right]},\left[\underline{k_{2}}, k_{2} c, \overline{k_{2}}\right]\right.$ are the structural parameters. Here, 
TABLE 2: (a) Comparison between the desired and the ANN values of $k_{1}, k_{2}, k_{3}, k_{4}$, and $k_{5}$ for a ten-storey shear structure. (b) Comparison between the desired and the ANN values of $k_{6}, k_{7}, k_{8}, k_{9}$, and $k_{10}$ for a ten-storey shear structure.

(a)

\begin{tabular}{lcccccccccc}
\hline $\begin{array}{l}\text { Data } \\
\text { number }\end{array}$ & $k_{1}$ (Ann) & $k_{1}$ (Des) & $k_{2}$ (Ann) & $k_{2}$ (Des) & $k_{3}$ (Ann) & $k_{3}$ (Des) & $k_{4}$ (Ann) & $k_{4}$ (Des) & $k_{5}($ Ann $)$ & $k_{5}($ Des $)$ \\
\hline 1 & 116900.6563 & 114999.7254 & 23626.293 & 23947.0748 & 25255.905 & 24299.2141 & 29078.6982 & 29493.0391 & 27766.1413 & 28842.8102 \\
2 & 137413.4659 & 135922.821 & 22400.1311 & 21970.538 & 22076.7651 & 22160.1892 & 28671.6078 & 29898.7215 & 23928.6799 & 23185.2425 \\
3 & 174166.5579 & 171165.6706 & 26751.8243 & 27587.6627 & 28439.4836 & 28089.9027 & 28056.19 & 27636.7332 & 28909.5075 & 29349.7909 \\
4 & 185745.6345 & 187147.6518 & 28203.5977 & 29952.1598 & 23288.5994 & 23565.0893 & 25414.2964 & 25588.2055 & 24175.8385 & 24794.8455 \\
5 & 131376.8088 & 132868.9612 & 22531.4396 & 21865.7144 & 20887.9013 & 20732.4343 & 22490.5032 & 21838.4294 & 21747.4496 & 22317.9161 \\
6 & 174687.251 & 165011.8025 & 25813.5863 & 27811.4527 & 25015.1015 & 25909.9146 & 25615.7328 & 24979.4882 & 24612.1573 & 23962.9025 \\
7 & 185115.3655 & 197483.6148 & 24841.291 & 21957.9798 & 27352.9705 & 29101.8783 & 25184.1779 & 25178.456 & 27414.6225 & 27050.7748 \\
8 & 107439.5782 & 107596.7361 & 28408.1614 & 29923.5897 & 22079.0745 & 21937.6594 & 29361.5732 & 29942.4301 & 25283.6014 & 25585.5903 \\
9 & 164872.2954 & 158701.9167 & 25498.9862 & 28022.6157 & 26269.1879 & 24323.6779 & 28505.5766 & 28548.5168 & 27421.7863 & 27566.307 \\
10 & 134496.3197 & 136428.6869 & 23984.6699 & 23091.3643 & 26528.5422 & 27288.6387 & 20735.4877 & 20391.8449 & 26590.0291 & 26789.4101 \\
\hline
\end{tabular}

(b)

\begin{tabular}{lcccccccccc}
\hline $\begin{array}{l}\text { Data } \\
\text { number }\end{array}$ & $k_{6}($ Ann $)$ & $k_{6}(\mathrm{Des})$ & $k_{7}$ (Ann) & $k_{7}$ (Des) & $k_{8}$ (Ann) & $k_{8}(\mathrm{Des})$ & $k_{9}($ Ann $)$ & $k_{9}$ (Des) & $k_{10}($ Ann $)$ & $k_{10}(\mathrm{Des})$ \\
\hline 1 & 21170.0974 & 20899.5068 & 25777.6655 & 25605.5953 & 28204.3487 & 29899.5021 & 27503.4171 & 25859.8704 & 27163.5463 & 25814.4649 \\
2 & 22417.1364 & 20549.7415 & 27621.6492 & 28654.3859 & 27612.505 & 28451.7819 & 28303.9996 & 29823.0322 & 22093.3505 & 22094.0508 \\
3 & 29672.9685 & 29638.7013 & 25998.8211 & 27124.1481 & 22438.2305 & 21982.2179 & 26315.5549 & 26153.251 & 27684.8546 & 29019.9081 \\
4 & 19962.2582 & 19656.5635 & 21156.2588 & 20166.7471 & 22269.5196 & 21950.7153 & 23818.7821 & 23766.1108 & 27240.5745 & 27020.6645 \\
5 & 20161.805 & 20514.4829 & 25387.6098 & 28009.2088 & 23922.4631 & 23268.3965 & 27519.8427 & 28771.8175 & 23219.6412 & 23774.551 \\
6 & 22307.0935 & 23043.4895 & 21527.1166 & 21425.0932 & 27311.6444 & 28803.3786 & 27670.7454 & 27848.5243 & 27234.7985 & 27349.5593 \\
7 & 27804.4452 & 25801.9183 & 24442.8169 & 24784.7447 & 25319.1653 & 24711.0187 & 25870.6554 & 24649.5428 & 27640.8021 & 29541.0279 \\
8 & 25509.2344 & 25309.6445 & 22738.1369 & 22568.3535 & 23936.8813 & 24039.6937 & 28924.1116 & 28139.7693 & 25172.6749 & 25428.1311 \\
9 & 28341.8519 & 29012.0809 & 25380.1928 & 23690.9169 & 23071.1828 & 21792.3148 & 28034.5751 & 28984.4414 & 26519.4395 & 25401.0583 \\
10 & 27911.2912 & 29624.314 & 26475.8553 & 24319.8061 & 21306.3632 & 21696.0881 & 25327.5363 & 24074.5574 & 24485.2563 & 23343.2942 \\
\hline
\end{tabular}

TABLE 3: Comparison between the desired and the ANN values of $\widetilde{K}$ for a single-storey shear structure.

\begin{tabular}{lcccccc}
\hline Data number & $\underline{K}($ Ann $)$ & $\underline{K}($ Des $)$ & $K c($ Ann $)$ & \multicolumn{1}{c}{ Kc (Des) } & $\bar{K}($ Ann $)$ & $\bar{K}($ Des $)$ \\
\hline 1 & 124932.9319 & 124189.1286 & 135932.8213 & 135095.2381 & 191905.7285 & 190281.611 \\
2 & 135763.4956 & 140411.2146 & 152464.2896 & 151324.954 & 191726.9669 & 194488.719 \\
3 & 110291.5736 & 109665.4525 & 141591.1084 & 140180.8034 & 148514.9196 & 149096.4092 \\
4 & 107394.0584 & 107596.6692 & 115134.7117 & 113217.3293 & 149119.797 & 148935.2638 \\
5 & 124430.5911 & 123991.6154 & 134455.7107 & 133781.941 & 192947.0787 & 194225.0591 \\
6 & 112574.5401 & 112331.8935 & 188853.0283 & 190015.3846 & 194542.4439 & 195633.454 \\
7 & 120988.7913 & 118390.7788 & 138166.8698 & 136934.6781 & 157619.3944 & 157540.8595 \\
8 & 108960.7756 & 105997.9543 & 113526.3083 & 111130.2755 & 126504.2017 & 123995.2526 \\
9 & 124700.9011 & 123497.9913 & 143556.5197 & 141726.7069 & 179985.5092 & 178035.2068 \\
10 & 105227.009 & 104965.443 & 135988.057 & 135335.8571 & 140612.991 & 138983.8837 \\
\hline
\end{tabular}

masses are assumed to be constant (as mentioned earlier). So, we will identify the stiffness parameter in fuzzy form using the fuzzy form of the frequency where frequency may be obtained from some experiments. In the following paragraphs, we have used the proposed method to identify the stiffness parameter for one-, two-, five-, and ten-storey frame structures. Here, we have considered the cases with crisp data for five- and ten-storeys and then fuzzified data for one- and two-storeys. The training data are also considered with the influence of noise, namely, in terms of triangular fuzzy number data. Accordingly we have considered the following four cases: 
TABLE 4: Comparison between the desired and the ANN values of $\widetilde{K}$ for a single-storey shear structure.

\begin{tabular}{lcccccc}
\hline Data number & $\underline{k}(\mathrm{Ann})$ & $\underline{k}(\mathrm{Des})$ & $k c($ Ann $)$ & $k c(\mathrm{Des})$ & $\bar{k}($ Ann $)$ & $\bar{k}(\mathrm{Des})$ \\
\hline 1 & 62365.0341 & 62104.5643 & 67644.4378 & 67547.619 & 95458.8463 & 95145.8055 \\
2 & 67613.8959 & 70215.6073 & 75826.931 & 75662.477 & 95893.1612 & 97249.3595 \\
3 & 55005.0087 & 54842.7263 & 70556.3936 & 70090.4017 & 74368.7997 & 74553.2046 \\
4 & 53128.7186 & 53798.3346 & 56947.542 & 56618.6646 & 74261.1768 & 74472.6319 \\
5 & 62246.1626 & 61995.8077 & 66881.2194 & 66895.9705 & 96278.4523 & 97122.5295 \\
6 & 55957.2602 & 56165.9467 & 94391.1219 & 95012.6923 & 97271.6645 & 97826.727 \\
7 & 60056.7259 & 59195.3894 & 68223.7328 & 68472.3391 & 78385.7211 & 78780.4298 \\
8 & 53587.3374 & 53008.9771 & 55747.5298 & 55570.1378 & 61968.3882 & 61997.6263 \\
9 & 62126.6388 & 61758.9957 & 71196.546 & 70863.3535 & 89991.9346 & 89022.6034 \\
10 & 52238.7913 & 52482.7215 & 67702.5259 & 67677.9286 & 69679.1387 & 69496.9418 \\
\hline
\end{tabular}

TABLE 5: (a) Comparison between the desired and the ANN values of $\widetilde{k}_{1}$ for a double-storey shear structure. (b) Comparison between the desired and the ANN values of $\widetilde{k}_{2}$ for a double-storey shear structure.

(a)

\begin{tabular}{lcccccc}
\hline $\begin{array}{l}\text { Data } \\
\text { number }\end{array}$ & $\underline{k_{1}}(\mathrm{Ann})$ & $\underline{k_{1}}(\mathrm{Des})$ & $k_{1} c($ Ann $)$ & $k_{1} c($ Des $)$ & $\overline{k_{1}}($ Ann $)$ & $\overline{k_{1}}(\mathrm{Des})$ \\
\hline 1 & 113258.5422 & 113317.1008 & 133858.2555 & 133969.3413 & 162741.2326 & 162807.3359 \\
2 & 116526.66 & 117338.8613 & 128622.4646 & 129208.408 & 193447.2534 & 195183.0465 \\
3 & 139119.0131 & 139093.7802 & 143501.0894 & 143175.117 & 191801.5675 & 192053.204 \\
4 & 101316.7594 & 101558.7126 & 106512.8803 & 105287.6998 & 183040.5812 & 183137.9743 \\
5 & 173554.7972 & 173805.8096 & 180269.037 & 180336.4392 & 198199.4731 & 198416.3724 \\
6 & 105985.8857 & 106047.1179 & 117592.2043 & 116726.841 & 127688.8972 & 126931.9426 \\
7 & 110472.1362 & 110631.6345 & 140132.9188 & 139925.7771 & 142461.6007 & 142303.5615 \\
8 & 137120.3743 & 137250.974 & 152856.9037 & 152687.5831 & 155005.6994 & 154807.0901 \\
9 & 119783.849 & 119821.8403 & 142480.6438 & 141679.9468 & 195824.6624 & 194293.6984 \\
10 & 141708.5217 & 141794.4104 & 148654.6797 & 148978.7638 & 165370.4902 & 165685.9891 \\
\hline
\end{tabular}

(b)

\begin{tabular}{lcccccc}
\hline $\begin{array}{l}\text { Data } \\
\text { number }\end{array}$ & $\underline{k_{2}}(\mathrm{Ann})$ & $\underline{k_{2}}(\mathrm{Des})$ & $k_{2} c($ Ann $)$ & $k_{2} c(\mathrm{Des})$ & $\overline{k_{2}}($ Ann $)$ & $\overline{k_{2}}(\mathrm{Des})$ \\
\hline 1 & 58488.0205 & 58566.0533 & 91472.5908 & 92796.1403 & 99954.016 & 99152.6233 \\
2 & 51977.6459 & 51640.041 & 65679.199 & 65072.7474 & 85856.2114 & 82258.2268 \\
3 & 69213.7504 & 68833.6105 & 77764.8854 & 78069.9896 & 85939.2478 & 85054.9378 \\
4 & 60124.2902 & 59566.1848 & 83319.0924 & 83316.9426 & 93794.9834 & 94103.325 \\
5 & 71317.3378 & 71432.6496 & 76748.5343 & 76956.3233 & 83930.3883 & 83468.7652 \\
6 & 59384.591 & 59531.6634 & 73687.8221 & 74121.1031 & 85087.5853 & 84905.276 \\
7 & 56031.7629 & 56050.5807 & 68215.603 & 68455.8273 & 83728.3652 & 83326.3957 \\
8 & 58849.1438 & 58906.6227 & 72741.8224 & 73046.2969 & 79796.3231 & 79495.3742 \\
9 & 57077.8681 & 56400.72 & 61035.9761 & 61329.384 & 95110.8992 & 99091.8975 \\
10 & 57858.7023 & 57830.2476 & 69404.8867 & 69250.9562 & 99433.354 & 99954.0197 \\
\hline
\end{tabular}

Case(i): Five-storey shear structure with crisp data,

Case(ii): Ten-storey shear structure with crisp data,

Case(iii): Single-storey shear structure with fuzzified data,
Case(iv): Double-storey shear structure with fuzzified data.

Computer programs have been written and tested for variety of experiments for the above cases. For the first two cases, namely, Case(i) and Case(ii), the inputs are taken as the crisp 
TABLE 6: (a) Comparison between the desired and the ANN values of $\widetilde{k}_{1}$ for a double-storey shear structure. (b) Comparison between the desired and the ANN values of $\widetilde{k}_{2}$ for a double-storey shear structure.

(a)

\begin{tabular}{lcccccc}
\hline $\begin{array}{l}\text { Data } \\
\text { number }\end{array}$ & $\underline{k_{1}}($ Ann $)$ & $\underline{k_{1}}(\mathrm{Des})$ & $k_{1} c($ Ann $)$ & $k_{1} c($ Des $)$ & \multicolumn{1}{c}{$\overline{k_{1}}($ Ann $)$} & $\overline{k_{1}}(\mathrm{Des})$ \\
\hline 1 & 62193.4503 & 62149.2679 & 65871.2249 & 66562.894 & 69219.2648 & 69672.8181 \\
2 & 71578.6175 & 71235.4748 & 71816.4848 & 72130.1157 & 83311.5254 & 83571.557 \\
3 & 63514.5116 & 63533.5212 & 84447.6191 & 84399.8043 & 86708.0123 & 87062.8972 \\
4 & 59459.7849 & 59872.6899 & 67907.0231 & 67971.4105 & 75148.6421 & 76002.6234 \\
5 & 67809.323 & 67385.6336 & 85655.9802 & 86827.0037 & 91460.6917 & 91106.0592 \\
6 & 57879.7498 & 57499.8627 & 69206.8111 & 69745.3738 & 71387.5577 & 71516.0705 \\
7 & 77679.4222 & 79304.6034 & 83870.4195 & 84180.7933 & 93380.175 & 94408.5477 \\
8 & 63484.2106 & 63107.2659 & 69028.8134 & 69579.1498 & 85313.0398 & 85212.3715 \\
9 & 52329.6174 & 52222.7046 & 72316.9085 & 72125.2707 & 88399.7894 & 88475.7194 \\
10 & 50895.5951 & 50988.8812 & 69532.938 & 69859.5759 & 87547.575 & 87746.6634 \\
\hline
\end{tabular}

(b)

\begin{tabular}{lcccccc}
\hline $\begin{array}{l}\text { Data } \\
\text { number }\end{array}$ & $\underline{k_{2}}($ Ann $)$ & $\underline{k_{2}}(\mathrm{Des})$ & $k_{2} c($ Ann $)$ & $k_{2} c(\mathrm{Des})$ & $\overline{k_{2}}($ Ann $)$ & $\overline{k_{2}}(\mathrm{Des})$ \\
\hline 1 & 27396.6322 & 27507.0572 & 27776.8241 & 27698.5425 & 28078.4211 & 28085.141 \\
2 & 21439.7109 & 21682.5355 & 27548.5904 & 27550.771 & 29081.9724 & 28275.8382 \\
3 & 23717.5546 & 23773.9554 & 27948.7301 & 27919.6303 & 28617.4807 & 28629.8048 \\
4 & 22090.0439 & 22160.1892 & 23180.7111 & 23205.2425 & 28962.7934 & 29908.7215 \\
5 & 25086.5697 & 25154.2346 & 25465.6455 & 25360.6413 & 27961.1253 & 27904.0722 \\
6 & 20724.6386 & 20919.5068 & 28645.592 & 28852.8102 & 29353.9707 & 29493.0391 \\
7 & 20706.4881 & 21137.0574 & 23381.0249 & 23275.6543 & 25716.8788 & 25890.2606 \\
8 & 21056.3736 & 21382.9255 & 21574.7879 & 21557.5235 & 26851.9289 & 26712.6437 \\
9 & 22075.9397 & 22008.6282 & 24479.3131 & 24386.4498 & 27062.0237 & 26806.523 \\
10 & 24070.1411 & 24079.5484 & 25009.5776 & 24971.7702 & 28009.5803 & 28335.006 \\
\hline
\end{tabular}

frequency values and the outputs are the stiffness parameters which are also in crisp form. On the other hand, for Cases(iii) and (iv), the inputs are taken as the fuzzified frequency values and the outputs are the stiffness parameters again in fuzzified form in the developed Fuzzy Neural Network (FNN) algorithm.

For the first case, an example of a storey shear structure is taken where the masses are $m_{1}=m_{2}=m_{3}=m_{4}=$ $m_{5}=36000$ and the stiffness parameters are within the range $k_{1}=\left[\begin{array}{ll}100000 & 200000\end{array}\right], k_{2}=$ [50000 100000], $k_{3}=\left[\begin{array}{ll}40000 & 60000\end{array}\right], k_{4}=\left[\begin{array}{ll}30000 & 50000\end{array}\right]$, and $k_{5}=$ [20000 30000]. A comparison between the desired and ANN values has been presented in Table 1. This table has been plotted in Figure 3.

In Case(ii), an example for a ten-storey shear structure has been considered with constant masses similar to Case(i) and the stiffness parameters are in the range $k_{1}=$ [100000 200000], $k_{2}=k_{3}=k_{4}=k_{5}=k_{6}=k_{7}=k_{8}=$ $k_{9}=k_{10}=\left[\begin{array}{ll}20000 & 30000\end{array}\right]$. The desired and ANN values for $k_{1}$ to $k_{5}$ and $k_{6}$ to $k_{10}$ are compared in Tables $2(\mathrm{a})$ and $2(\mathrm{~b})$, respectively.

For Case(iii), the first example is that of a single-storey shear structure with masses $\widetilde{M}=36000$ and the stiffness parameters lie within the range $\underline{K}=\left[\begin{array}{ll}100000 & 200000\end{array}\right], K c=$ [100010 200010], and $\bar{K}=\left[\begin{array}{ll}100020 & 200020\end{array}\right]$. A comparison between desired and the ANN values has been incorporated in Table 3. This table has been plotted in Figure 4. In the second example, a single-storey shear structure is considered with masses $\widetilde{M}=36000$ and the stiffness parameter varying within the range $\underline{K}=\left[\begin{array}{l}50000 \\ 100000\end{array}\right], K c=$ [50010 100010], and $\bar{K}=[50020$ 100020]. Comparison between the desired and the ANN values is tabulated in Table 4 and is plotted in Figure 5.

In Case(iv), the first example of a double-storey shear structure is considered where the masses are $\widetilde{m}_{1}=\widetilde{m}_{2}=$ 36000 and the stiffness parameters varying within the range $k_{1}=\left[\begin{array}{ll}100000 & 200000\end{array}\right], k_{1} c=\left[\begin{array}{ll}100010 & 200010\end{array}\right]$, $\overline{k_{1}}=\overline{[100020}$ 200020] and $k_{2}=\left[\begin{array}{ll}20000 & 30000\end{array}\right], k_{2} c=$ [20010 30010], and $\overline{k_{2}}=\left[\begin{array}{ll}20020 & 30020\end{array}\right]$. The desired and ANN values have been compared in Tables 5(a) and 5(b). This table has also been shown in Figures 6(a) and 6(b). In the second example, a double-storey shear structure is implemented with masses $\widetilde{m}_{1}=\widetilde{m}_{2}=36000$ and the stiffness parameters having the range $k_{1}=\left[\begin{array}{lll}50000 & 100000\end{array}\right]$, $\left.k_{1} c=\left[\begin{array}{ll}50010 & 100010\end{array}\right], \overline{k_{1}}=\overline{[50020} 100020\right]$ and 
TABLE 7: (a) Comparison between the desired and the ANN values of $k_{1}, \overline{k_{1}}$ and $k_{2}, \overline{k_{2}}$ for a double-storey shear structure for $\alpha=0.3$. (b) Comparison between the desired and the ANN values of $\underline{k_{1}}, \overline{k_{1}}$ and $\underline{k_{2}}, \overline{k_{2}}$ for a double-storey shear structure for $\alpha=0.5$. (c) Comparison between the desired and the ANN values of $\underline{k_{1}}, \overline{k_{1}}$ and $\underline{k_{2}}, \overline{\overline{k_{2}}}$ for a double-storey shear structure for $\alpha=0.8$.

(a)

\begin{tabular}{lcccccccc}
\hline $\begin{array}{l}\text { Data } \\
\text { number }\end{array}$ & $\underline{k_{1}}(\mathrm{Ann})$ & $\underline{k_{1}}(\mathrm{Des})$ & $\overline{k_{1}}(\mathrm{Ann})$ & $\overline{k_{1}}(\mathrm{Des})$ & $\underline{k_{2}}($ Ann $)$ & $\underline{k_{1}}(\mathrm{Des})$ & $\overline{k_{2}}($ Ann $)$ & $\overline{k_{2}}(\mathrm{Des})$ \\
\hline 1 & 109470 & 109250 & 124660 & 123870 & 63676 & 63908 & 81668 & 81670 \\
2 & 119370 & 119420 & 141760 & 141590 & 59687 & 59772 & 79075 & 78865 \\
3 & 141840 & 141880 & 154360 & 154170 & 63017 & 63149 & 77680 & 77561 \\
4 & 126590 & 126380 & 179820 & 178510 & 58265 & 57879 & 84888 & 87763 \\
5 & 143790 & 143950 & 160360 & 160670 & 61323 & 61256 & 90425 & 90743 \\
\hline
\end{tabular}

(b)

\begin{tabular}{lcccccccc}
\hline $\begin{array}{l}\text { Data } \\
\text { number }\end{array}$ & $\underline{k_{1}}(\mathrm{Ann})$ & $\underline{k_{1}}(\mathrm{Des})$ & $\overline{k_{1}}(\mathrm{Ann})$ & $\overline{k_{1}}(\mathrm{Des})$ & $\underline{k_{2}}($ Ann $)$ & $\underline{k_{1}}(\mathrm{Des})$ & $\overline{k_{2}}($ Ann $)$ & $\overline{k_{2}}(\mathrm{Des})$ \\
\hline 1 & 111790 & 111390 & 122640 & 121830 & 66536 & 66826 & 79388 & 79513 \\
2 & 125300 & 125280 & 141300 & 141110 & 62124 & 62253 & 75972 & 75891 \\
3 & 144990 & 144970 & 153930 & 153750 & 65795 & 65976 & 76269 & 76271 \\
4 & 131130 & 130750 & 169150 & 167990 & 59057 & 58865 & 78073 & 80211 \\
5 & 145180 & 145390 & 157010 & 157330 & 63632 & 63541 & 84419 & 84602 \\
\hline
\end{tabular}

(c)

\begin{tabular}{lcccccccc}
\hline $\begin{array}{l}\text { Data } \\
\text { number }\end{array}$ & $\underline{k_{1}}(\mathrm{Ann})$ & $\underline{k_{1}}(\mathrm{Des})$ & $\overline{k_{1}}(\mathrm{Ann})$ & $\overline{k_{1}}(\mathrm{Des})$ & $\underline{k_{2}}($ Ann $)$ & $\underline{k_{1}}(\mathrm{Des})$ & $\overline{k_{2}}($ Ann $)$ & $\overline{k_{2}}(\mathrm{Des})$ \\
\hline 1 & 115270 & 114590 & 119610 & 118770 & 70827 & 71203 & 75968 & 76278 \\
2 & 134200 & 134070 & 140600 & 140400 & 65779 & 65975 & 71318 & 71430 \\
3 & 149710 & 149600 & 153290 & 153110 & 69963 & 70218 & 74153 & 74336 \\
4 & 137940 & 137310 & 153150 & 152200 & 60244 & 60344 & 67851 & 68882 \\
5 & 147270 & 147540 & 152000 & 152320 & 67096 & 66967 & 75411 & 75392 \\
\hline
\end{tabular}

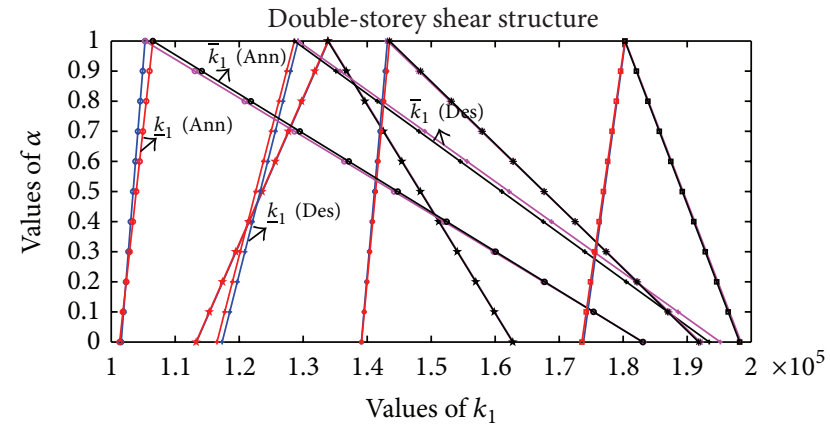

(a)

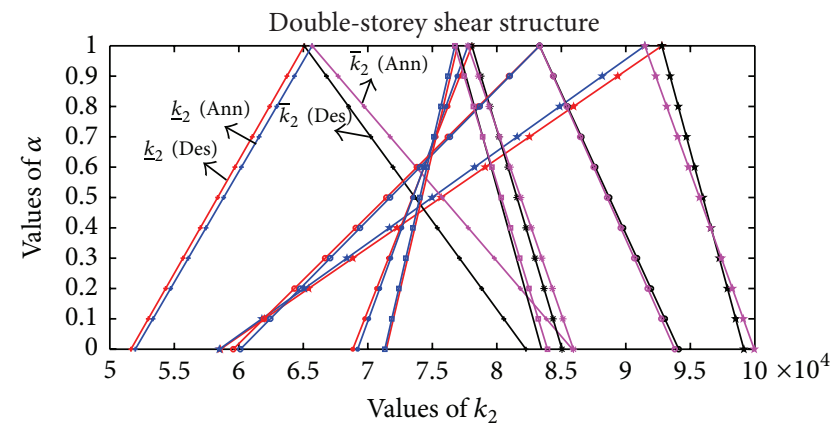

(b)

FIgURE 9: (a) Comparison of $\underline{k_{1}}$ and $\overline{k_{1}}$ with respect to $\alpha$. (b) Comparison of $\underline{k_{2}}$ and $\overline{k_{2}}$ with respect to $\alpha$.

$\underline{k_{2}}=\left[\begin{array}{ll}20000 & 30000\end{array}\right], k_{2} c=\left[\begin{array}{ll}2001030010\end{array}\right]$, and $\overline{k_{2}}=$ [20020 30020]. Comparison between the desired and ANN values are again incorporated in Tables 6(a) and 6(b). This table is plotted in Figures 7(a) and 7(b).
The training data with the influence of noise for two-storey shear structure in TFN form for five sets of data have been presented here. Accordingly, Figures 8(a) and 8(b) refer the fuzzy plot of frequency. Moreover, the Triangular 
Fuzzy Number (TFN) plots of identified stiffness are cited in Figures 9(a) and 9(b). Also for different alpha values such as $\alpha=0.3, \alpha=0.5$, and $\alpha=0.8$, the comparison between the desired and ANN values with another five sets of data has been given in Tables 7(a), and 7(b), and 7(c).

\section{Conclusion}

Here, the procedure is demonstrated to identify stiffness parameters for multistorey shear structure using fuzzified data in ANN. The present study considers example problems of one-, two-, , and ten-storey shear structures. Identification study for and ten-storey shear structures has been done with crisp data. Then, fuzzified data has been considered for oneand two-storey shear structures for the present identification procedure. Initial design parameters, namely, stiffness and mass and so the frequency of the said problem is known in term of fuzzy numbers. The engineers want to know the present health of the structure by system identification methods. It is assumed that only the stiffness is changed and the mass remains the same. The present values of the frequencies may be obtained by available equipments, and using these, one may get the present parameter values by ANN. So, if sensors are placed to capture the frequency of the floors in fuzzy (uncertain) form, then, those may be fed into the proposed new ANN model to get the present stiffness parameters. The methods of one- and two-storey shear structures with fuzzified data may very well be extended for higher storey structures following the present procedure. As regards the influence of noise, it may be seen that the input and output data for two-storey shear structure are actually in terms of Triangular Fuzzy Number (TFN) which themselves dictate the noise in both monotonic increasing and decreasing senses. In order to train the new ANN model, set of data are generated numerically beforehand. As such, converged ANN model gives the present stiffness parameter values in fuzzified form for each floor. Thus, one may predict the health of the structure. Corresponding example problems (as mentioned) have been solved, and related results are reported to show the reliability and powerfulness of the model.

\section{Acknowledgments}

The authors would like to acknowledge funding from the Ministry of Earth Sciences, New Delhi, India. They are also thankful to the anonymous reviewers for their valuable suggestion to improve the paper.

\section{References}

[1] E. Khanmirza, N. Khaji, and V. J. Majd, "Model updating of multistory shear buildings for simultaneous identification of mass, stiffness and damping matrices using two different softcomputing methods," Expert Systems with Applications, vol. 38, no. 5, pp. 5320-5329, 2011.

[2] M. I. Friswell, D. J. Inman, and D. F. Pilkey, "The direct updating of damping and stiffness matrices," AIAA Journal, vol. 36, no. 3 , pp. 491-493, 1998.
[3] M. Tanaka and H. D. Bui, Inverse Problems in Engineering Mechanics, Balkema, Rotterdam, The Netherlands, 1994.

[4] K. F. Alvin, A. N. Robertson, G. W. Reich, and K. C. Park, "Structural system identification: from reality to models," Computers and Structures, vol. 81, no. 12, pp. 1149-1176, 2003.

[5] S. D. Fassois and J. S. Sakellariou, "Time-series methods for fault detection and identification in vibrating structures," Philosophical Transactions of the Royal Society A, vol. 365, no. 1851, pp. 411-448, 2007.

[6] S. F. Marsi, G. A. Bekey, H. Sassi, and T. K. Caughey, "Nonparametric identification of a class of non-linear multidegree dynamic systems," Earthquake Engineering \& Structural Dynamics, vol. 10, no. 1, pp. 1-30, 1982.

[7] P. Ibanez, "Review of analytical and experimental techniques for improving structural dynamic models," Welding Research Council Bulletin, no. 249, 1979.

[8] A. K. Datta, M. Shrikhande, and D. K. Paul, "System identification of buildings: a review," in Proceedings of 11th Symposium on Earthquake Engineering, University of Roorkee, Roorkee, India.

[9] C.-H Loh and I.-C Tou, "A system identification approach to the detection of changes in both linear and non-linear structural parameters," Earthquake Engineering \& Structural Dynamics, vol. 24, no. 1, pp. 85-97, 1995.

[10] P. Yuan, Z. Wu, and X. Ma, "Estimated mass and stiffness matrices of shear building from modal test data," Earthquake Engineering and Structural Dynamics, vol. 27, no. 5, pp. 415-421, 1998.

[11] C. H. Chen, "Structural identification from field measurement data using a neural network," Smart Materials and Structures, vol. 14, no. 3, pp. S104-S115, 2005.

[12] C. S. Huang, S. L. Hung, C. M. Wen, and T. T. Tu, "A neural network approach for structural identification and diagnosis of a building from seismic response data," Earthquake Engineering and Structural Dynamics, vol. 32, no. 2, pp. 187-206, 2003.

[13] C. Y. Kao and S. L. Hung, "Detection of structural damage via free vibration responses generated by approximating artificial neural networks," Computers and Structures, vol. 81, no. 28-29, pp. 2631-2644, 2003.

[14] Z. Wu, B. Xu, and K. Yokoyama, "Decentralized parametric damage detection based on neural networks," Computer-Aided Civil and Infrastructure Engineering, vol. 17, no. 3, pp. 175-184, 2002.

[15] B. Xu, Z. Wu, G. Chen, and K. Yokoyama, "A localized identification method with neural networks and its application to structural health monitoring," Journal of Structural Engineering A, vol. 48, pp. 419-427, 2002.

[16] B. Xu, Z. Wu, G. Chen, and K. Yokoyama, "Direct identification of structural parameters from dynamic responses with neural networks," Engineering Applications of Artificial Intelligence, vol. 17, no. 8, pp. 931-943, 2004.

[17] S. Chakraverty, "Identification of structural parameters of multistorey shear buildings from modal data," Earthquake Engineering and Structural Dynamics, vol. 34, no. 6, pp. 543$554,2005$.

[18] M. J. Perry, C. G. Koh, and Y. S. Choo, "Modified genetic algorithm strategy for structural identification," Computers and Structures, vol. 84, no. 8-9, pp. 529-540, 2006.

[19] G. S. Wang, "Application of hybrid genetic algorithm to system identification," Structural Control and Health Monitoring, vol. 16, no. 2, pp. 125-153, 2009. 
[20] S. Yoshitomi and I. Takewaki, "Noise-bias compensation in physical-parameter system identification under microtremor input," Engineering Structures, vol. 31, no. 2, pp. 580-590, 2009.

[21] Y. Lu and Z. Tu, "A two-level neural network approach for dynamic FE model updating including damping," Journal of Sound and Vibration, vol. 275, no. 3-5, pp. 931-952, 2004.

[22] C. G. Koh, Y. F. Chen, and C. Y. Liaw, "A hybrid computational strategy for identification of structural parameters," Computers and Structures, vol. 81, no. 2, pp. 107-117, 2003.

[23] H. Tang, S. Xue, and C. Fan, "Differential evolution strategy for structural system identification," Computers and Structures, vol. 86, no. 21-22, pp. 2004-2012, 2008. 

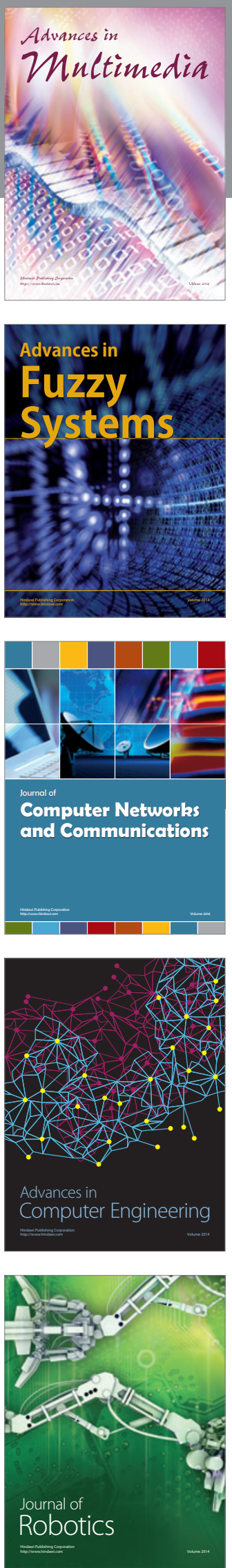

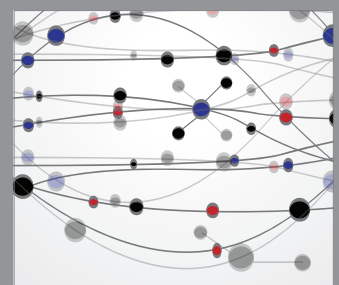

The Scientific World Journal
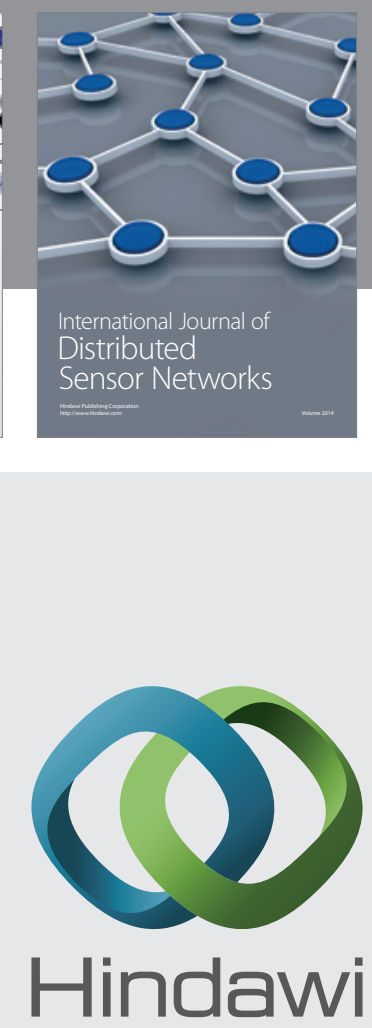

Submit your manuscripts at

http://www.hindawi.com
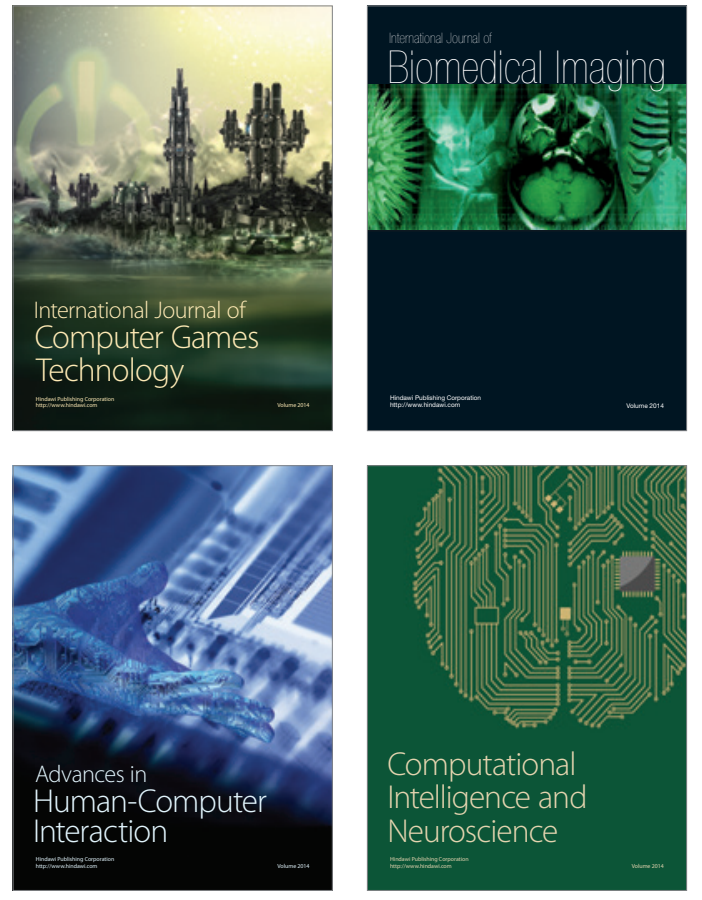
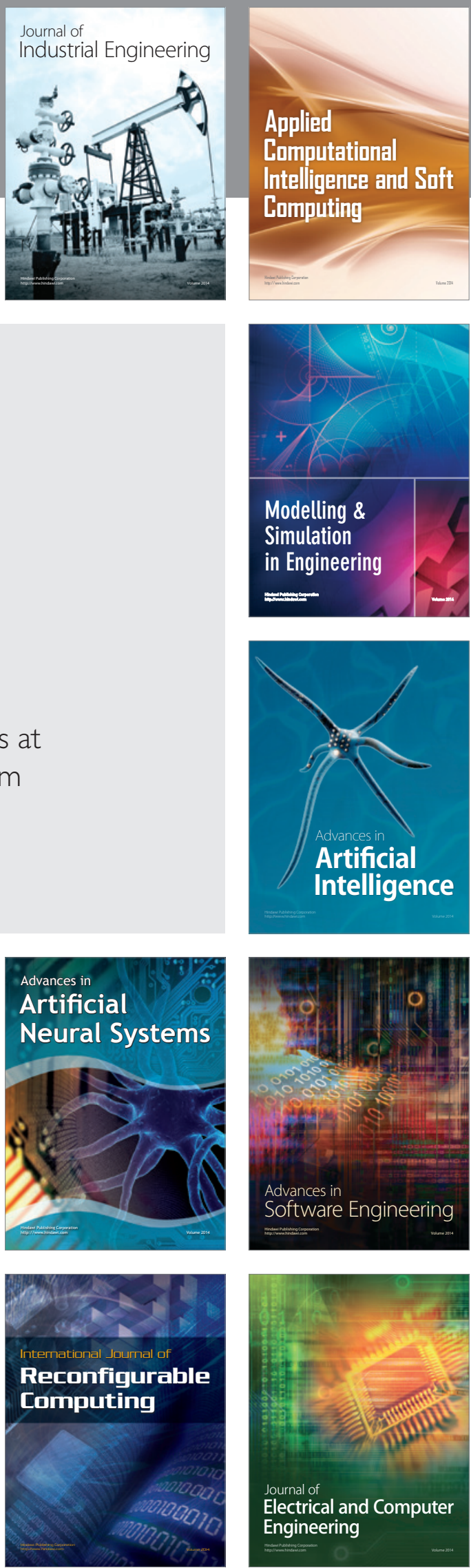